\title{
Playing for fun or gambling for money: a qualitative longitudinal study of digitally simulated gambling among young Danes
}

\author{
Søren Kristiansen, Maria Camilla Trabjerg, Nanna Reventlov Lauth and Anders Malling
}

\begin{abstract}
Purpose - The study aims to explore the types of simulated games and gambling platforms used by adolescents, adolescent's experiences, motivations and behaviors vis-à-vis simulated gambling and the potential interrelationships between simulated and monetary forms gambling.

Design/methodology/approach - Data was obtained from a qualitative longitudinal panel study with three waves of individual interviews. A cohort of 51 young Danes, with varying levels of gambling involvement, were interviewed three times, with a 10-12 frequency from 2011 to 2014. In total, 149 interviews were conducted over the 4-year period.

Findings - Enjoying social interactional effects appeared to be the main reasons young people engage in simulated gambling games. The study documented characteristics of both a catalyst pathway and a containment pathway emphasizing that for some young people simulated gambling may increase the likelihood of involvement in real money gambling while it may decrease it for others.

Research limitations/implications - The sample was relatively limited and it involved participants from only one of the five Danish regions. The sample reflects the culture, rural/urban configuration and gambling market of a specific geographic region.

Practical implications - Some forms of simulated digital gambling may provide players with excitement and unrealistic conceptions of winning chances, which, in turn, may encourage participation in real forms of gambling. This may call for regulatory policies aiming at the structural features of simulated gambling products and their rapid global spread. Consumer campaigns aimed at both young people themselves and their parents may be considered.

Originality/value - Few studies have provided insights into the meanings and motivations of young people engaged in simulated gambling. The current study is among the first to explore adolescent's experiences, motivations and behaviors vis-à-vis simulated gambling and the potential interrelationships between simulated and monetary forms gambling.
\end{abstract}

Keywords Adolescence, Longitudinal, Consumer socialization, Simulated gambling

Paper type Research paper

\section{Introduction}

Globally, gambling is a widespread activity among young people, and for the majority, it constitutes a harmless pastime activity (Dean, 2011). In recent years, there has been a significant increase in the range of available online gambling activities (Gainsbury et al., 2012; Griffiths and Parke, 2010; King et al., 2010), and internet gambling has been desribed as one of the fastest growing gambling-related industries (Schaffer et al., 2010). As a result, contemporary youth live in environments "where gambling opportunities continue to grow, are widely available and viewed as socially acceptable forms of entertainment" (Derevensky \& Gilbeau, 2015). Also, as recent research have suggested, "the increased availability of legal gambling appears to have led to some increases in the prevalence of adolescent
Søren Kristiansen is an

Associate Dean at Aalborg

University, Aalborg,

Denmark.

Maria Camilla Trabjerg is

based at Aalborg

University, Aalborg,

Denmark.

Nanna Reventlov Lauth is a

Team Tech Manager at

RadioAnalyzer, Aalborg,

Denmark.

Anders Malling is a

Research Assistant at

Aalborg University,

Aalborg, Denmark.

Received 3 November 2017

Revised 6 March 2018

Accepted 3 April 2018

() Søren Kristiansen,

Maria Camilla Trabjerg, Nanna Reventlov Lauth and Anders Malling. Published by Emerald Publishing Limited.

This article is published under the Creative Commons Attribution (CC BY 4.0) licence. Anyone may reproduce, distribute, translate and create derivative works of this article (for both commercial and non-commercial purposes), subject to full attribution to the original publication and authors. The full terms of this licence may be seen at http:// creativecommons.org/licences/ by/4.0/legalcode 
gambling and to the development of gambling problems among young people" (Calaldo et al., 2017, p. 397).

This study examines an emerging and related area of concern, namely, simulated digital gambling among young people. The term simulated digital gambling covers a range of online, money free gambling activities that are offered through various online platforms (social media, apps and websites). The marketing and consumer protection in relation to these new games are not regulated the same way as monetary gambling, and recent research indicates that advertisements often use imagery that appeal to young adults (Abarbanel et al., 2016). Also, there has been some evidence that the use of sound are somewhat similar in some forms of social casino games and their money-based counterparts, which may reduce players' ability to distinguish between the two forms (Bramley and Gainsbury, 2014). In the research literature, simulated gambling is defined as "digitally simulated interactive gambling activity that does not directly involve monetary gain but is otherwise structurally identical to the standard format of a gambling activity owing to its wagering features and chance-determined outcomes of play" (King et al., 2014, p. 305). Thus, simulated digital gambling is money-free online forms of gambling that share certain characteristics with other gambling forms as it involves wagering and some element of chance. With the expansion of the internet, the convergence of online and social gambling, and as prices of mobile phones, tablets and laptops decrease, simulated gambling becomes a fast-growing gambling industry. In a blue paper, Morgan Stanley estimated that this type of gambling could grow up to \$7billion by 2015 (Morgan Stanley, 2012).

\section{Review of literature}

\section{Characteristics of simulated digital youth gambling}

Recent empirical research on simulated digital youth gambling have shown that these activities are popular among young people and that they may serve as predictors of gambling problems among young people. In a qualitative study among young Australians aged 15-24, Allen et al. (2008) identified two different outcomes of simulated digital gambling: "For a small number of young people the use of practice play is cited as one of the factors that influence their future intention to gamble. For others however, involvement with online practice play or computer based gambling games results in a decreased desire to participate in future monetary gambling they tire easily of the games, and develop a sense of how quickly money can be lost" (Allen et al., 2008, p. 9). In the UK, Griffiths and Wood (2007) conducted a survey of 8,017 young people aged between 12 and 15 years of age. Among those who reported having played lottery on the internet, 28 per cent had played free demo games. Volberg et al. (2008) conducted a survey of gambling and problem gambling among Oregon adolescents based on a sample of 1,555 adolescents aged 12 to 17 years of age. It was found that lifetime gambling participation was the highest for playing free gambling-type games on the internet. In a sample of 1,287 Australian adolescents aged 12-17 years of age, King et al. (2014) found that 13 per cent reported involvement in simulated gambling during the last 12 months, and that participants with past involvement in simulated digital gambling had a higher risk of endorsing indicators of pathological gambling.

\section{Migration from simulated to monetary forms of gambling}

There has been some concern that adolescent simulated gambling may lead young people into monetary gambling activities (Derevensky and Gupta, 2007; King and Delfabbro, 2016). As many online gambling providers offer "practice versions" next to their monetary and real gambling activities and as underage people can engage in these activities, a potential convergence of simulated gambling and money gambling has been noted (King et al., 2010; Derevensky and Gainsbury, 2015). Also, it has been suggested that in 
simulated gambling activities, young people may practice and learn the principles of real gambling and have positive experiences without the risk of losing money (Griffiths, 2013). Such suggestions are supported by research showing that some simulated gambling activities may provide inadequate conceptions of winning chances (Sévigny et al., 2005).

A significant concern is related to the relationship between simulated online gambling and forms of gambling involving real money. Studies among adults have found that people who engage in simulated digital gambling are more likely to engage internet-based gambling with real money and to experience gambling problems compared to people not playing these games (Gainsbury et al., 2014; Kim et al., 2015). At present, however, evidence is needed in terms of whether simulated forms of gambling motivates migration to monetary online gambling for people with no such previous experience (Kim et al., 2015). In a recent qualitative study involving ten adult social casino users, Gainsbury et al. (2015) have identified some associations between free-to-play gambling such as activities and monetary forms of gambling. Some respondents reported that belonging to a network of players was an important factor in terms of their engagement in simulated gambling, while involvement in social casino games did not seem to affect the likelihood of gambling or the risk of problem gambling.

At present, very little research has examined the links between young people's participation in simulated online gambling and other forms of gambling. However, some research has indicated that among young people, social casino use influence actual gambling expenditure especially among those young who are at the risk of gambling-related problems (Gainsbury et al., 2016). Other research has shown that some young people switch back and forth between money gambling and social casino games, indicating that these activities provide similar experiences (Teichert et al., 2017; King et al., 2016). Also, a qualitative study among college students (Gupta et al., 2013) found some evidence of transition from simulated to monetary gambling. While it may be hypothesized that wing to the similarities in structural characteristics and the potential convergence of simulated and monetary forms of gambling, participation in simulated online gambling increase the likelihood of engaging in real forms of gambling, this link has yet not been examined in detail empirically. While there is some evidence suggesting a positive relationship between simulated gambling and monetary gambling (King et al., 2014), findings are based on cross-sectional design and, thus, do not allow conclusions as to whether simulated online gambling leads to monetary gambling. As noted by King and Delfabbro (2016, p. 203), "there is need for prospective longitudinal studies that assess youth involvement in financial and simulated gambling activities". To address the knowledge gap and the call made by King and Delfabbro, this study was designed to investigate qualitatively and longitudinally how young people experience online simulated gambling, the relations between online simulated gambling and other monetary forms of gambling and the potential processes of transition from simulated to monetary forms of gambling. This study was also designed to providing insights into the meanings and motivation of the young people engaged in simulated gambling and, thus, to exploring some of the complexities involved in or underlying the processes of transition. More specifically, the study was designed to explore (a) the types of simulated games and gambling platforms used by adolescents, (b) adolescent's experiences, motivations and behaviors vis-à-vis simulated gambling and (c) the potential interrelationships between simulated and monetary forms gambling.

\section{Research design, methods and sample}

The findings presented here are based on a qualitative longitudinal study of gambling behavior among young Danish people, designed as a panel study, with three waves of individual interviews. A cohort of 51 young Danes with varying levels of gambling involvement were interviewed three times with a 10-12 frequency from 2011 to 2014 . Thus, 51 participated in the first wave, 50 in the second wave and 48 in the third wave of 
interviews. In total, 149 individual interviews were conducted, 48 participants were interviewed 3 times. Interviews lasted from 30 minutes to 1 hour. The qualitative longitudinal design allows explorations of the young participant's experiences of simulated gambling as well as insights into the processes and dynamics involved in gambling trajectories. As further details on method, sampling and procedures have been described in other publications from the study (Kristiansen et al., 2014 and 2016), a brief summary is provided here.

On the basis of surveys conducted in a number of primary schools, a technical college and a high school in the Aalborg region in North of Jutland, participants for interviews were recruited. The questionnaire used in the survey contained a modified version of a youthadapted gambling screen, the South Oaks Gambling Screen - Revised for Adolescents, SOGS-RA (Winters et al., 1993a, 1993b), while each subsequent interview involved the full SOGS-RA questionnaire. In addition to this, and specifically to obtain a sufficient number of participants with possible gambling problems, a snowballing-procedure was used as participants who had already been interviewed were contacted, asking them to forward an interview invitation to potential participants with gambling experience. Also, a post was placed on a gambling-related site on Facebook (Kristiansen et al., 2016, p. 368). In the final selection of participants for interview, efforts were made to obtain an equal number of participants in each gambling category and to ensure variation in terms of age, gender, school type and residence.

To leave room for participant's rich narrative accounts and letting the informants ascribe meaning to their gambling behavior, interviews were semi-structured and focused on preselected themes such as initial gambling experiences, present gambling behavior, perceived availability, self-perceived gambling abilities, friends and social networks. Also, each interview sweep had a distinct focus. The first sweep focused on early gambling experiences, the second on current gambling behavior and the third on perceptions of gambling (for additional information, see Kristiansen et al., 2016). All interviews were digitally recorded and transcribed in full length. Data management and analysis was facilitated by QSR Nvivo software package 10, and the coding procedure was inspired by the principles of thematic analysis (Braun and Clarke, 2006). To identify analytical themes, all transcripts of interviews were subject to open coding, and from this, a broad selection of categories was identified. While conducting further exploration and searching in the data, initial categories were refined and used as nodes in the following coding process. To trace and explore transitions across the three sweeps of interview, each interview document were assigned a sweep number which enabled various searches in the entire dataset using combinations of attribute values (sweep numbers) and selected nodes (for additional information, see Kristiansen et al., 2016, p. 369).

\section{Findings}

While focusing on the young participant's experiences and perceptions of simulated gambling activities, we explored three themes across our data. First, the types of games played and the contexts of the initial experiences were investigated. Second, the motivations and effects related to simulated gambling were analyzed, and finally, we explored the potential links between simulated gambling and gambling involving real money. In the following, citations from transcripts are marked with participant's gender, age and sweep number.

\section{Simulated gambling: types of games and contexts of experience}

Our analysis revealed distinct ways in which the informants encounter virtual simulated games. First, some informants "stumble" upon the game, suggesting an accidental discovery of the medium, either through an advertisement or by looking for other games. 
Second, some informants actively seek out these games with deliberate intent. Third, for those who have stumbled upon virtual simulated games, previous knowledge is not required to begin their engagement with online poker or other types of simulated games. Our data suggest a distinction between the three types of platforms in regards to the differences in the "recruitment" process among the three types of games, focusing primarily on the ease of transition participants may experience into real-world, monetary gambling. These differences and distinctions in game recruitment are based on evidence from our participants but by the nature of the platforms themselves. Even though the three platforms are similar in regard to them providing a means to play poker against other people, they have distinct qualities in regard to recruitment. First, Facebook is a platform many young people already use frequently (Correa et al., 2010). According to our data, participants do not sign up to Facebook to play poker, but rather poker is introduced through website exploration. This makes the virtual setting they are in more familiar and thereby "less dangerous" from the participants observed perspective. This familiarity, coupled with promotion of simulated gambling through advertisement, we would argue, is why Facebook poker is so "successful" in our sample. Second, similar to Facebook in regard to "intent" of the individual are online gaming sites as a platform for poker. These websites offer a multitude of interactive online games as a form of entertainment, with only some of these games that a participant may choose from being poker. From what we understand of our informants in this study, a characteristic to this platform is the intent of players not visiting these websites with the intent of only playing poker. In this manner, online gaming websites provide a similar interactive experience, where participants stumble upon playing poker through happenstance and website promotion through advertisement or site layout. The third platform-type is Poker Clients. In this platform, one most likely has an intention to play poker owing to the way it is not submerged within a preexisting platform. Although one may discover Poker Clients through some type of advertisement, one must still download the program and sign up for it, resulting in the participant explicitly knowing what they are involving themselves in. This demands more determination by the participating individual and may explain why relatively few informants are playing with "fun money" on a client as opposed to real money. Once players begin playing with "fun money", they begin playing without any investment - allowing them to become familiar to the setting, situation and experience - which, thus, normalizes it. Once a participant feels comfortable and has formed him/herself as a successful participant in the platform, depositing money and transitioning into real-world currency seem to be relatively easy. Participating with real world currency looks no different than the VGS, further increasing the familiarity of the setting. Additionally, Poker Clients often encourages one to continue playing by promoting interaction through the offering of "free-rolls". "Free-rolls" allow for the participant to play in a tournament without the concern of losing actual money, while offering to the participant the possibility to gain real-world money. These three categories suggest an inherent hierarchical nature that deal with the participant's initial intent. This initial intent, however, may develop from an interactive experience with the first platform (Facebook), to engaging with an interactive experience with the second platform (online gaming), which may ultimately lead to engagement with the third platform (Poker Clients). This type of transition is not a strict processional guideline that one must follow. However, owing to the nature of Facebook, a large number of participants may find their initial engagement with simulated gambling may be initiated from such an already familiar platform.

The types of games participants prefer reflect a clearly gendered pattern. Games that simulate gambling, e.g. poker on Facebook, are an almost entirely male preserve, while female participants tend to prefer gaming. The most popular type of simulated gambling mentioned by participants was Texas Hold'em poker. Often, participants mentioned simulating gambling on social media such as Facebook. Others stated that they use Y8. dk (Playpilot.com), a website that hosts a wide range of free games. A number of participants stated that they use apps for smartphones and tablets. These apps are often linked with 
social media, providing the opportunity to play with friends. Several participants specifically mentioned the social aspect of simulated gambling. One male participant said:

I've played poker on Facebook and from time to time in my class at school. But it's not something I do at home. It's mainly at school during boring classes. It'll pop up in Facebook Messenger:

'Fancy a game of poker?' and five or six of us from the class will join a virtual table. (Male, 17, $T_{2}$ )

This is one example of a situation in which young people play games that simulate gambling. A male participant mentioned that Facebook poker is something to be played with classmates at school, not a lonesome leisure pursuit. For him, simulated gambling is a social phenomenon, an alternative to "boring classes" at school. Several other participants stated that they first encountered this type of game because their classmates were playing them. For example, a female participant said, "Some of the guys in our class played it a lot during lessons and I thought, "Hmm, maybe I should give it a go?'” (Female, 16, $\mathrm{T}_{2}$ ). This is an example of how big a role social circles play in determining young people's gambling behavior. Several of the participants were introduced to simulated gambling by friends, either at school or through invitations sent via social media. Several participants indicated that simulated gambling is an activity indulged in with others at school. They find it fun to have something in common about which the teacher knows nothing.

\section{Motivation and effects}

The lack of winnings in the form of cash differentiates simulated gambling from conventional gambling. Monetary gains, therefore, are not the primary motive for engaging in simulated digital gambling. In the sections below, we explore the motivations of the young players as well as the effects that the engagement provides.

\section{Digitally facilitated sociality}

The data indicate that simulated gambling is an activity that a number of participants turn to when alone in the physical sense but that the social aspect is still a highly significant part of the overall experience, as they usually play along with friends and acquaintances. Social media provide opportunities to compete against people on their friends list. Although social media replace face-to-face relationships, the social aspect is retained in the sense that the players have a relationship to each other and the chat function facilitates communication. The social relationship and the joy of playing with others are embedded in what is referred to as a "screen-to-screen" relationship. These relationships allow young people to talk tactics and help each other to improve their game skills even if they are not physically in the same room. Below, one young man explains how he uses Facebook to play with friends online:

It's like you can see who's online, who plays the game and who doesn't. So you spot that him, and him and him are playing and you see if you can't get everybody at the same table for a game together. (Male, 15, $T_{1}$ )

Before the quote above, the participant had expressed that he found it more entertaining to play against friends because the feeling of winning is different when you know your opponent. His description shows how young people use social media to find people they know who play the same games as they do and play together. Very few participants said that they only play on their own, in private and against random, unknown opponents. Often, these participants did not know whether others in their social circle play similar games. In summary, the data show that young people's access to simulated gambling to a large extent goes via social media. The game mentioned most often by participants was the poker simulation Texas Hold'em. Via Facebook, players are able to invite friends for a game, which means they can play with people from their social circle despite not being in the 
same physical location. This means that social interactions and social control are still part of the game because it is possible to communicate with known partners and opponents.

\section{Learning rules and effects}

When asked how they learned to gamble, the majority of participants mentioned simulated gambling on Facebook. They explain that these games provide an opportunity for young people to learn the rules, try out different strategies and improve their skills without risking financial loss. One young man recalled how he learned about poker on Facebook:

When you start playing poker on Facebook, you have 10,000, and there are tables for different amounts. There's something called the small blind and the big blind, which is how much you have to put down to be in on the round. The table where I won 50,000,000 had a 10,000 blind, and I couldn't keep up the first time I played. (Male, 14, $T_{1}$ )

The quote illustrates how the participant learned to use the terminology you need to be able to play poker. He mentions that he could not really keep up the first time he tried it. This reflects a progression as it means by implication that he is now capable of keeping up. He has learned the rules and specific language of poker. The statement shows that the participant was on an initial step in the learning process the first time he played. He did not know the techniques and could not really keep up, as he put it. He has subsequently progressed and learned to gamble correctly. In this manner, simulated gambling serves as a legitimate arena in which young people can practice their gambling skills. They are not violating formal rules such as gambling legislation or informal ones such as social norms about whether it is acceptable for young people to gamble. Another young man explains that he learned to play Blackjack via simulation games:

Participant:I play Blackjack.

Interviewer: Are you good at it?

Participant: I think so. Yes, I am. Some people are really good but I can play at any rate. I know what to do.

Interviewer: Where did you learn?

Participant: Where did I learn to play? I think it was on Facebook, or with friends, just playing for fun. You can play on Facebook.

Interviewer: Can you play Blackjack on Facebook?

Participant: Oh yes. You can play anything on Facebook.

Interviewer: So you play for "Facebook money", or what?

Participant: Yes, exactly. (Male, 17, $\mathrm{T}_{1}$ )

This young man used games he played "for fun" to learn the rules and improve his skills. He also said that Facebook offers every type of game and, therefore, many opportunities for enhancing skills. He later explained that, for him, there is a clear distinction between online and offline gambling. He is dubious of the online version - both simulated and real - a skeptical view based on a belief that the odds are stacked in the provider's favor: "[...] I don't believe you can win. And suddenly you've lost the lot. I think it's part of the system, that they've made it that way" (Male 17, $\mathrm{T}_{1}$ ). Via simulated gambling, young people learn the games and improve their skills without running the risk of financial loss. Also, they may learn about game designs and their winning chances. In this specific participant's case, this means that he has noticed that the provider usually wins. This skepticism may indicate that his early experience with simulated gambling will limit future involvement in real gambling. However, not all participants share such skepticism. Several express similar views on both simulated gambling and games involving real money. This is reflected in the reactions when 
the participants were asked to explain their strategies for playing with virtual money that holds no real value. This is how one male participant responded to the question of whether he tends to gamble or play safe:

Participant: I always play safe.

Interviewer: Okay, so it's not that you're thinking, you've got 2.5 million so you might as well?

Participant: No, cos you'd soon burn your way through 2.5 million that way. It's always at the back of my mind - don't lose anything. (Male, 16, $T_{1}$ )

This individual attributes a form of value to the virtual money. This interpretation is based on the caution expressed in his statement that he always plays safe. The majority of participants express a similar sense of pleasure about winning in simulated gambling. It may be "false money", but a big win still means something. Many of the participants are also annoyed when they "lose money". This is owing to the competitive element, which is a major aspect of simulated gambling. Another male participant explained why he plays these games on Facebook:

Participant: [...] I think if you like the game, like the whole gambling thing, the taking chances and are willing to lose money, then I reckon you could soon get hooked, cos I was once, even though I was just doing it for fun. I just HAD to be on Facebook every day and play cos I was determined not to be the worst. I just had to do it every day, and in the end I almost couldn't stop, so...

Interviewer: Did you think about it every day?

Participant: I thought about it a fair bit, cos I knew I really didn't want to be the worst, so I had to play to be the best. I managed, but was soon back at the bottom again when I lost the 3 million. It wasn't as much fun after that. (Male, 15, $T_{1}$ )

It clearly matters a great deal to this participant how he ranks at Facebook poker compared to his friends. "It's about not being the worst", as he puts it. The virtual money score is a way of showing who is in the lead and, conversely, who is "worst". These statements show that the participants are not indifferent about losing this otherwise worthless "money". Virtual "money" has value for the participants. It is a sign of ability. They may not be running any risk of financial loss, but the potential loss of status endows this otherwise worthless money with a real value for them. As demonstrated, the social element is of great importance to the young people concerned. Simulated gambling brings them together for several reasons. A main aspect around which they coalesce is keeping it secret from their teachers. There is a certain degree of excitement associated with doing something surreptitious together instead of what they are supposed to be doing, i.e. following what is going on in class.

\section{Competition}

Several participants mention the competitive element as a motivation for their involvement. Male participants in particular express that it is very much about status, about who is the best within a given social circle. Social media allow winnings to be saved as virtual money and they can see which of their friends is in the lead by looking at how much "money" each of them has. Several participants describe a big "win" as a special sensation. One male participant recalls how he reacted when he won millions of virtual Facebook money:

Participant: Well you post it on your Facebook timeline and write "Ha ha! I'm number one!" Interviewer: Do you look up to mates who are good at poker?

Participant: Yeah, we do a bit, yeah. It's kind of hard to explain.

Interviewer: What's it like to win 16 million on Facebook? 
Participant:Well, obviously, it's great to win, and it's really cool to be number one on that list.

Interviewer: Because it gains you respect?

Participant: Yes. It's like you're a bit better than the others [...] I know that I'm the best at poker among my mates, and it's a good feeling. (Male, 14, $\mathrm{T}_{1}$ )

This participant describes very accurately why young people get involved in simulated gambling, and it is highly reminiscent of descriptions of real gambling. It seems, then, that simulated gambling may provide the same feeling of success or euphoria as real gambling. Players experience the same feelings of prestige and pride when they win, and their results are shared with friends in the same manner. Their feelings are identical to those expressed by other participants about real gambling. Another participant explained his motivation for proper gambling, specifically poker:

[...] if there's one thing I really get into when it comes to poker, it's the online rankings. I can see where my name is on it and how good I am and I get a real buzz out of that - out of the prestige. I want to be one of the best. That's definitely part of the draw for me [...] it's not so much about the money as about the prestige of being near the top of the rankings. I'm 16th, so I'm pretty close, but it costs a lot of money to play all the time and improve your ranking. The top players are usually the same every week. It's as if a lot of them just about live off sitting there $[\ldots]\left(\right.$ Male, $\left.21, \mathrm{~T}_{3}\right)$

For many of the young participants an important motivation is about being the best. In other words, their position in the rankings means more to them than the actual wins. One major driving force is the opportunity to assert themselves over their peers, to compete on status. What these young people seek in simulated gambling, then, are feelings of euphoria, pride and prestige. These feelings are quantified in terms of virtual money which endows this otherwise worthless currency with a form of value.

\section{Relationships between monetary and simulated gambling}

Our data suggest that it is difficult for some young people to recognize the consequences of switching from simulated gambling to the real thing. This is because the games share the same structural characteristics with the notable difference - that the latter involves real money, while the former does not. Some participants even report not being sure sometimes whether they were playing a simulated game or gambling for real. One young man talked about switching from simulation to the real thing:

So l've won say 800,000 in [... . of course you don't actually win it, it's just for fun. But sometimes, I think maybe I could do this for real, man [... S Some companies give you 30 to get started, but you have to be over 18. We tried it once at my mate's place, but we didn't win anything. Then, it asked us to pay up, and we were a bit unsure whether we had done something wrong cos we had played for real money. (Male, 13, $T_{1}$ )

This participant's statement shows how it can be difficult for some young people to distinguish between simulation and real gambling. For others, this transition is more clearly perceived. One young man explained how he started out with simulated gambling on Facebook before progressing to the real thing:

Participant: It looked like fun, so I started playing poker on Facebook, Texas Hold'em and the likes and built up a pile of virtual money. That's one of the reasons I thought l'd be good at poker, cos I won several million on Facebook.

Interviewer: So it is for fun?

Participant: Yes, it's for fun. I won several million but when I tried playing for real money | lost. (Male, 18, $\mathrm{T}_{1}$ ) 
The quote from this young man illustrates how simulated gambling helped boost his confidence in his own luck and gambling skills. He started to believe that his skills could be transferred to and helpful in real gambling. We may argue, then, that simulated and real gambling can be viewed as two structurally similar activities producing similar effects. In turn, this indicates that the online simulated gambling games experienced by the participants in this study operate by the same variable ratio reinforcement schedules originally proposed by Skinner (1953), as a behavioral explanation of gambling behavior. Such schedules are similar to the so-called random ratio schedules of reinforcement, which have been described as "particularly relevant for certain types of games" (James et al., 2017, p. 613). With their unpredictable reward structure, such reinforcement schedules may work to keep the young player's pseudo-gambling behavior going, and it may enable them "to feel more comfortable with gambling per se, which may assist the transition from simulated gambling to gambling with real money" (Griffiths et al., 2014, p. 334). The narrative of the participant described above illustrates how players may attempt to extend a "career" in simulated gambling into real gambling while pursuing well-known effects. While he did not succeed in terms of monetary winnings, he enjoyed the same thrill and continued to play in an attempt to recoup his losses. Through simulations, this participant has learned to enjoy gambling and its effects. The simulations seem to have given him the confidence and courage to play poker for real money and the fact that he won several million in virtual currency may have affected his beliefs and ideas of his gambling abilities. Our data contains other examples of individuals who have taken "the step" from simulation to real gambling. For example, in the third sweep of interviews, one young man said that he only plays poker with his friends at the moment but that he learned the rules and concepts via simulations:

Interviewer: Where did you learn about the big blind and small blind?

Participant: Via Facebook poker [...] you can lose as much as you like on there without any comebacks, it's pretty cool. (Male, 15, T3)

This young man explained how he uses techniques learned playing Facebook poker when now playing for money. For him, real gambling has replaced simulated gambling. Simulated gambling gave the participant knowledge of the game, demystifying it so it no longer felt unknown and dangerous. This helped him in the transition to playing real poker with his friends. He plays a couple of times a month in games where the friends all put in DKK 200 in DKK 10 coins, which they use as chips. About real gambling, he said:

Interviewer: Let's say you win DKK 600. What's the best bit - the money or feeling that you're the best?

Participant: You get a little kick, you feel you're a bit better than the others, and it's nice to win 600 as well.

Interviewer: Why is it important to be better than the others?

Participant: It isn't really, ha ha, but there's just something cool about it. I think it's something that I got from playing handball. It characterizes almost everything I do.

Interviewer: That you've got to be the best?

Participant: Yeah - at least I want to be better than the others anyway.

Interviewer: Is that why you think it's fun, the competition?

Participant: Yeah, l'd say so, cos if it was just for the money, l'd probably join a game with a bigger pot and play a bit more often. So no, it's not for the money. (Male, 15, T3)

These statements illustrate the ease of this young man's transition from gambling-simulation games to real gambling. Instead of playing for virtual money, he and his friends now play for real cash. The participant describes how the appeal of the game lies in the "kick" he gets 
from beating his friends. Winning the pot is just a bonus; the effect he seeks is prestige. Several of our participants with experience of simulated gambling went on to try the real thing with simulated gambling serving as a kind of learning platform. The longitudinal nature of this study with three waves of interviews allowed us to explore these transitions across individual participants. The trajectory of one young male participant based on data from all three waves of interviews, may illustrate and exemplify: In the first interview, he narrated retrospectively on how he, at the age of nine, played a chat-based online game called Harboe, where he and a friend spend real money on virtual furniture that they gambled on in game casinos:

It was a game called Dansk Harboe and I became friends with a lot of people in there. And there was also something called Casino, where we played with dices and wagered, perhaps some furniture. We found out how the cheat the system and also how we could exchange furniture with other players (Male, 13, $T_{1}$ )

At this time, this participant also played some VSG poker, and at $T_{2}$ VSG poker really picked up pace and took up a substantial of his spare time, to the extent that he negated his girlfriend and homework:

Then, I started to play poker again, and some friends and I became very involved in this. Some days, I came home from school and ignored my homework to be able to play poker; this happened quite frequently. We decided to wager money as we felt we were quite skilled players. (Male, 14, $\mathrm{T}_{2}$ )

After this, which was evident at $T_{3}$, he started to venture in the world of sport betting where played a lot and lost money in a rather short time span: "Oh yeah, I did that [sport betting] a lot during the summer and fall, me and my friends did that a lot". (Male, 14, $T_{3}$ )

\section{Discussion}

In this study, we set out to address the call for longitudinal and qualitative research in the field of simulated digital youth gambling. Our main findings support some of the most prevalent hypotheses in this field. Researchers (Griffiths and Wood, 2007, p. 26) have contended that children and young people may learn how to gamble on digital free-to-play gambling activities as these activities allow them to familiarize themselves with the principles and excitements of gambling without experiencing loss of real money. Our data have documented such learning and socialization processes as some of the participants prepared for monetary gambling through forms of simulated digital gambling. To paraphrase the works of Howard Becker (1963, p. 58), some young people learn to gamble, learn to recognize and enjoy the effects of real monetary gambling and to connect them with gambling activities by engaging in simulated forms of gambling. In Denmark, and in many other countries and jurisdictions, there are no restrictions preventing children and adolescents playing (and learning how to gamble) on these practice and demonstration modes. In this manner, children are being introduced to the principles and excitement of gambling without experiencing the consequences of losing money. In other words, these young consumers "are able to experience the basic mechanics of gambling without the requirement of spending money" (Gainsbury et al., 2017, p. 338). In addition, this study found that Facebook is a popular conduit for simulated gambling and that the social element is important to the young people involved. Enjoying social interactional effects (such as pride, prestige and competitive elements) appeared to be the main reasons young people engage in these games. These finding are in line with previous research indicating that young people start gambling not only owing to purely personal characteristics but also through social processes and significant social networks, where knowledge is shared and meaning is learned and attributed to gambling experiences (Reith and Dobbie, 2011, 2012). 
Our findings indicate that a proportion of participants use simulated digital gambling as training grounds to improve their gambling skills. They learn about gambling without any risk of financial loss, and in some cases, this process also involves learning about game designs. This may discourage future involvement with gambling and perhaps even prevent problem gambling as these young people may develop realistic understandings of winning chances. However, the data also show that the majority of the participants use simulated gambling as a gateway activity that enhances the desire, and to try the real thing and give them the courage to do so. For some participants, a big win in a simulated game may trigger an attempt at real gambling in the hope of winning just as big. Simulated gambling may, then, facilitate building up young people's self-confidence and give them hope of future success, thereby easing the transition to real gambling. We found that participants experienced the two types of games as very similar and that several of them developed the desire to gamble for real via simulated digital gambling. Our findings, thus, also seem to echo those of Gupta et al. (2013), who found that some youth learn to gamble by practicing at Facebook and that the similarities between simulated gambling and real online gambling activities may make it difficult for some to differentiate whether they are gambling for real or virtual money.

While there is a lack of research documenting causality between simulated and monetary gambling, some conceptual research has been conducted. From a review of empirical studies of simulated digital youth gambling, King and Delfabbro (2016) have proposed a two-pathway model conceptualizing the potential benefits and risk related to early exposure to various types of simulated gambling: a "catalyst pathway" describing risk factors associated with early exposure to simulated gambling and a "containment pathway" describing protective factors with potential to increase the likelihood of safe-gambling or disinterest in gambling activities. As far as the potential risks and positive effects of simulated gambling are concerned, our data has documented and illustrated characteristics of both a catalyst pathway and a containment pathway. Our data and research design however, allows no conclusive answer as to whether simulated gambling has a preventive effect or acts as a gateway for young people. This inconclusive statement is supported by the general finding that participants perceive, use and react to the games differently. However, the majority of participants who start out with simulated digital gambling progress to try conventional gambling with real money, often catalyzed by big wins in simulated games.

While our data do not allow any conclusions regarding the causal relationship between simulated online gambling and gambling for real money, many of the young participant's narratives illustrated behavioral pathways from digital simulated gambling to gambling with real money. On the basis of extensive field research in Las Vegas, Schull (2012) has shown how the rhythm and mechanics of machine gambling take gamblers into a subjective, trancelike state called "the machine zone". In this zone, they lose their normal sense of money, space, time and even their self. Machine gambling, in Schull's analysis are not, then, about money, it is about getting into the zone. Our findings suggests a somewhat similar interpretation: By engaging in simulated digital gambling, some of the young participants in this study learn to be in a type of gambling zone, where money - whether real or virtual - is not an end in itself. Money becomes a medium for gaining prestige and social rank. That is, they learn not only specific techniques and practices of real gambling in simulated versions, but also to recognize and appreciate the thrills, excitements, feelings of success and euphoria associated with gambling. They learn to engage in a competitive environment motivated by the prestige of being among the best. Thus, our data suggest that when playing some of these simulated games, with their designed payout schedule, the participants may enter into a state of "flow" (Csíkszentmihályi, 2014), where euphoric experiences keep them engaged in the activity that seems to be intrinsically rewarding. Our findings may also suggest that in certain simulated gambling games, some of the 
young players experience a particular reinforcement schedule that encourages them to continue playing. While our data do not allow conclusions regarding this, existing research show that certain gambling and social gaming activities make use of operant conditioning and random reinforcement schedules related to the unpredictability of wining or getting rewards (Parke and Griffiths, 2007; Griffiths et al., 2014). However, clearly more research is needed to explore and clarify the psychological mechanisms at play in various forms of online simulated gambling, which may help understand how players are induced to continue playing or to transition from simulated gambling to monetary gambling forms.

The findings presented in this study have some further theoretical and practical implications. Theoretically, our data indicate that young people engage in simulated gambling activities not purely owing to individual characteristics but for social reasons and owing to processes in significant social networks. Furthermore, migration from simulated digital gambling to gambling with real money seems to be associated, not solely with personal features but with learning and skill-building processes facilitated by the simulated gambling technology. The longitudinal nature of the study made it possible to identify trends in the participants' behavior over a three-year period. Clearly, future follow-up research would be useful to follow this cohort during transitions from youth to adulthood to provide insights into the processes and complexities involved in or underlying changes in gambling behaviors. In terms of policy, some of the findings indicate that there can be problems associated with early engagement in simulated gambling as it can provide young people with unrealistic conceptions of real gambling. The results indicate a need to focus on the possible consequences of simulated digital gambling for later involvement in real gambling. As our data suggests, some forms of simulated digital gambling (owing to the sophisticated game designs) may provide players with excitement and unrealistic conceptions of winning chances, which, in turn, may encourage participation in real forms of gambling. This may call for regulatory policies aiming at the structural features of these simulated gambling products as well as their rapid global spread. Supplementary, information and consumer campaigns aimed at both young people themselves and their parents may be considered. Previous studies (Derevensky and Gupta, 1997) have shown that family background and parental acceptance are important indicators of future gambling behavior, which makes it important that parents pay attention to the level of involvement by their offspring in both simulated and real gambling.

This study has limitations as well as strengths. Our sample was relatively limited and it involved participants from only one of the five Danish regions. The sample, then, reflects the culture, rural/urban configuration and gambling market of a specific geographic region (Kristiansen et al., 2016, p. 379). The findings presented here cannot, then, be generalized to other contexts and jurisdictions, but do provide qualitative insights into young people's experiences of online simulated gambling and the processes, meanings and motivations underlying transitions from simulated to monetary gambling. While bearing the geographical aspect in mind, it should be noted, however, that the focus in this study was primarily on online simulated gambling, which, to some extent, minimize the importance of the physical and geographical context. As for the strengths, the prospective design enabled us to follow the same cohort over a longer period. The fact that we stayed in contact with and interviewed the same people three times with specific frequencies allowed us to discuss participants gambling behavior and behavior changes with them in the specific social and cultural context, more or less as they were actually taking place. Also, this relatively close contact between researchers and participants made it possible to reduce recall bias and to build rapport, which, in turn, resulted in a very satisfactory level of attrition (Kristiansen et al., 2016, p. 379). 


\section{References}

Abarbanel, B., Gainsbury, S.M., King, D., Hing, N. and Delfabbro, P.H. (2016), "Gambling games on social platforms: how do advertisements for social casino games target young adults?", Policy and Internet, Vol. 9 No. 2, pp. 184-209.

Allen, K., Madden, J., Brooks, K. and Najman, J. (2008), "The virtual jackpot! The socio-cultural and environmental context of youth gambling", Report prepared for Queensland Treasury.

Becker, H. (1963), Outsiders: Studies in the Sociology of Deviance, The Free Press, New York.

Bramley, S. and Gainsbury, S.M. (2014), "The role of auditory features within slot-themed social casino games and online slot machine games", Journal of Gambling Studies, Vol. 31 No. 4, pp. 1735-1751, doi: 10.1007/s10899-014-9506-x.

Braun, V. and Clarke, V. (2006), "Using thematic analysis in psychology", Qualitative Research in Psychology, Vol. 3 No. 2, pp. 77-101.

Calaldo, F., Alexandre, J. and Griffiths, M. (2017), "Prevalence of adolescent problem gambling: a systematic review of recent research", Journal of Gambling Studies, Vol. 33 No. 2, pp. 397-424.

Csíkszentmihályi, M. (2014), Flow and the Foundations of Positive Psychology: The Collected Works of Mihaly Csıkszentmihályi, Springer, New York.

Correa, T., Hinsley, A.W. and Gil de Zúñiga, H. (2010), "Who interacts on the web? The intersection of users' personality and social media use", Computers in Human Behavior, Vol. 26 No. 2, pp. 247-253.

Dean, D.H. (2011), "A path model of perceived financial risk in casino blackjack", Young Consumers, Vol. 12 No. 1, pp. 15-26.

Derevensky, J.L. and Gilbeau, L. (2015), "Adolescent gambling: twenty-five years of research", The Canadian Journal of Addiction, Vol. 6, pp. 4-12.

Derevensky, J.L. and Gainsbury, S.M. (2015), "Social casino gaming and adolescents: should we be concerned and is regulation in sight?", International Journal of Law and Psychiatry, Vol. 44, doi: 10.1016/j. ijlp.2015.08.025.

Derevensky, J.L. and Gupta, R. (1997), " "Familial and social influences on juvenile gambling behavior", Journal of Gambling Studies, Vol. 13 No. 3, pp. 179-192.

Derevensky, J.H. and Gupta, R. (2007), "Internet gambling amongst adolescent: a growing concern", International Journal of Mental Health Addiction, Vol. 5 No. 2, pp. 93-101.

Gainsbury, S., King, D.L., Russell, A.M.T., Delfabbro, P. and Hing, N. (2017), "Virtual addictions: an examination of problematic social casino use among at-risk gamblers", Addictive Behaviors, Vol. 64 pp. 334-339.

Gainsbury, S.M., Russell, A. and Hing, N. (2014), "An investigation of social casino gaming among landbased and internet gamblers: a comparison of socio-demographic characteristics, gambling and co-morbities", Computers in Human Behavior, Vol. 33, pp. 126-135.

Gainsbury, S.M., Hing, N., Delfabbro, P., Dewar, G. and King, D.L. (2015), "An exploratory study of interrelationships between social casino gaming, gambling, and problem gambling", International Journal of Mental Health and Addiction, Vol. 13 No. 1, pp. 136-153, doi: 10.1007/s11469-0149526-x.

Gainsbury, S.M., Russell, A.M.T., King, D.L., Delfabbro, P. and Hing, N. (2016), "Migration from social casino games to gambling: motivations and characteristics of gamers who gamble", Computers in Human Behavior, Vol. 63, pp. 59-67.

Gainsbury, S.M., Wood, R., Russell, A., Hing, N. and Blaszczynski, A. (2012), "A digital revolution: comparison of demographic profiles, attitudes and gambling behaviour of internet and non-internet gamblers", Computers in Human Behavior, Vol. 28 No. 4, pp. 1388-1398.

Griffiths, M. (2013), "Social gambling via Facebook: further observations and concerns", Gaming Law Review and Economics, Vol. 17 No. 2, pp. 104-106.

Griffiths, M. and Wood, R. (2007), "Adolescent internet gambling: preliminary results of a national survey", Education and Health, Vol. 25 No. 2, pp. 23-27. 
Griffiths, M.D. and Parke, J. (2010), "Adolescent gambling on the internet: a review", International Journal of Adolescent Medicine and Health, Vol. 22 No. 1, pp. 59-75.

Griffiths, M.D., King, D.L. and Delfabbro, P.H. (2014), "The technological convergence of gambling and gaming practices", in Richard, D.C.S., Nower, L. and Blaszczynski, A. (Eds), The Wiley-Blackwell Handbook of Disordered Gambling, Wiley \& Sons, New York, pp. 327-345.

Gupta, R., Derevensky, J. and Wohl, M. (2013), "A qualitative examination of online gambling culture among college students: factors influencing participation, maintenance and cessation", Paper presented at the 15th International Conference on Gambling and Risk Taking, Las Vegas, NV.

James, R.J.E., O'Malley, C. and Tunney, R.J. (2017), "Understanding the psychology of mobile gambling: a behavioral synthesis", British Journal of Psychology, Vol. 108 No. 3, pp. 608-625.

Kim, H.S., Wohl, M.J.A., Salmon, M.M., Gupta, R. and Derevensky, J. (2015), "Do social casino gamers migrate to online gambling? An assessment of migration rate and potential predictors", Journal of Gambling Studies, Vol. 31 No. 4, pp. 1819-1831, doi: 10.1007/s10899-014-9511-0.

King, D.L. and Delfabbro, P.H. (2016), "Early exposure to digital simulated gambling: a review and conceptual model", Computers in Human Behavior, Vol. 55, pp. 198-206.

King, D., Delfabbro, P. and Griffiths, M. (2010), "The convergence of gambling and digital media: implications for gambling in young people", Journal of Gambling Studies, Vol. 26 No. 2, pp. $175-187$.

King, D.L., Delfabbro, P.H., Kaptsis, D. and Zwaans, T. (2014), "Adolescent simulated gambling via digital and social media: an emerging problem", Computers in Human Behavior, Vol. 31, pp. 305-313.

King, D.L., Russell, A., Gainsbury, S., Delfabbro, P.H. and Hing, N. (2016), "The cost of virtual wins: an examination of gambling related risks in youth who spend money on social casino games", Journal of Behavioural Addictions, Vol. 5 No. 3, pp. 401-409.

Kristiansen, S., Reith, G. and Trabjerg, M. (2016), "The notorious gambling class: patterns of gambling among young people in Denmark: a longitudinal qualitative study", Journal of Youth Studies, Vol. 20 No. 3, pp. 366-381, doi: 10.1080/13676261.2016.1232480.

Kristiansen, S., Trabjerg, M. and Reith, G. (2014), "Learning to gamble: early gambling experiences among young people in Denmark", Journal of Youth Studies, Vol. 18 No. 2, pp. 133-150, doi: 10.1080/ 13676261.2014 .933197$.

Morgan Stanley. (2012), "Social gambling: click here to play", Morgan Stanley Research Reports.

Parke, J. and Griffiths, M.D. (2007), "The role of structural characteristics in gambling", in Smith, G., Hodgins, D. and Williams, R. (Eds), Research and Measurement Issues in Gambling Studies, Elsevier, New York, pp. 211-243.

Reith, G. and Dobbie, F. (2011), "Beginning gambling: the role of social networks and environment", Addiction Research and Theory, Vol. 19 No. 6, pp. 483-493.

Reith, G. and Dobbie, F. (2012), "Gambling careers - a longitudinal study of gambling behaviour", Addiction Research and Theory, Vol. 21 No. 5, pp. 376-390.

Schaffer, H.J., Peller, A.J., LaPlante, D.A., Nelson, S.E. and LaBrie, R. (2010), "Toward a paradigm shift in internet gambling research: from opinion and self-report to actual behavior", Addiction Research \& Theory, Vol. 18 No. 3, pp. 270-283.

Schull, N.D. (2012), Addiction by Design: Machine Gambling in Las Vegas, Princeton University Press, Princeton, $\mathrm{NJ}$

Sévigny, S., Cloutier, M., Pelletier, M. and Ladouceur, R. (2005), "Internet gambling: misleading payout rates during the 'demo' period”, Computers in Human Behavior, Vol. 21 No. 1, pp. 153-158.

Skinner, B.F. (1953), Science and Human Behavior, Macmillan, New York.

Teichert, T., Gainsbury, S.M. and Mühlbach, C. (2017), "Positioning of online gambling and gaming products from a consumer perspective: a blurring of perceived boundaries", Computers in Human Behavior, Vol. 75, pp. 757-765.

Volberg, R.A., Hedberg, E.C. and Moore, T.L. (2008), Oregon Youth and Their Parents: Gambling and Problem Gambling Prevalence and Attitudes, Oregon Department of Human Services, Salem, OR. 
Winters, K.C., Stinchfield, R.D. and Fulkerson, J. (1993a), "Toward the development of an adolescent gambling problem severity scale”, Journal of Gambling Studies, Vol. 9 No. 1, pp. 63-84.

Winters, K.C., Stinchfield, R.D. and Fulkerson, J. (1993b), "Patterns and characteristics of adolescent gambling", Journal of Gambling Studies, Vol. 9 No. 4, pp. 371-386.

\section{Further reading}

King, D.L., Gainsbury, S.M., Delfabbro, P., Hing, N. and Abarbanel, B. (2015), "Distinguishing between gaming and gambling activities in addiction research", Journal of Behavioral Addictions, Vol. 4 No. 4, pp. 215-220.

Prensky, M. (2001), "Digital natives, digital immigrants", On the Horizon, Vol. 9 No. 5, pp. 1-6.

\section{Corresponding author}

Søren Kristiansen can be contacted at: samf-prodekan-forsk@aau.dk

For instructions on how to order reprints of this article, please visit our website: www.emeraldgrouppublishing.com/licensing/reprints.htm

Or contact us for further details: permissions@emeraldinsight.com 